\title{
Ligamentum Teres and its Analog in the Hip Endoprosthesis - Necessary or Superfluous? A Systematic Review
}

\author{
S. V. Arkhipov ${ }^{1,2}$, D. V. Skvortsov ${ }^{1}$ \\ ${ }^{1}$ Laboratory of Clinical Physiology and Biomechanics, Federal State Budgetary Institution "N.N. Priorov National \\ Medical Research Center of Traumatology and Orthopaedics" of the Ministry of Health of the Russian \\ Federation, Moscow, Russia \\ ${ }^{2}$ Department of Surgery, MEDSI Group of Companies, Moscow, Russia
}

\section{CORRESPONDING AUTHOR: \\ Sergey V. Arkhipov \\ Department of Surgery \\ MEDSI Group of Companies \\ Solyanka Streer 12/1 \\ 109240, Moscow, Russia \\ E-mail: archipovsv@gmail.com}

DOI:

10.32098/mltj.02.2021.13

LEVEL OF EVIDENCE: 1A

\begin{abstract}
SUMMARY
Background. Dislocation of hip endoprosthesis remains a common and serious complication of arthroplastic interventions. One of the ways to prevent endoprosthesis dislocation is to integrate a ligamentum teres analog into its design.

Purpose. Reviewing international experience in the design, development and insertion of hip endoprosthesis with the native ligamentum teres or its analog.

Materials and methods. A systematic patent and non-patent search and analysis of publications on hip endoprostheses with native ligamentum teres or its artificial analog. The search was done on relevant online platforms and in available libraries.

Results. To date, there are 20 identified patents on endoprosthesis designs with the native ligamentum teres or its analog. Ligamentum teres analogs are proposed to be created using auto-, allo- or xenografts, synthetic materials and metals. We have found two subtotal endoprosthesis with ligamentum teres analogs that are used in clinical practice. The long-term outcomes of such surgeries are not known. There are no commercially available endoprostheses with ligamentum teres analogs.

Conclusions. A ligamentum teres analog integrated into a hip endoprosthesis can help prevent dislocation in the post-operative period. Further theoretical, experimental, biomechanical and clinical studies are needed to develop such endoprostheses for a wider use.
\end{abstract}

\section{KEY WORDS}

Hip joint; ligamentum capitis femoris; ligamentum teres; endoprosthesis; complication; dislocation of a bip joint prosthesis.

\section{INTRODUCTION}

Hip arthroplasty has been widely used since the mid-1940searly 1950s (1-5). Soon after the start of a wide use of both cups and the more familiar endoprostheses, however, surgeons began to report cases of their dislocation and subluxation (6-13). Dislocation after hip replacement is a serious and devastating complication of such surgical interventions $(14,15)$. According to literature data, the incidence of dislocation reached $15 \%$ in the 1970s-1980s (16). These days, dislocation after primary arthroplasty occurs in $0.2-10 \%$ of the cases, more often for prostheses implanted after femoral neck fracture (17-22). The incidence of dislocation after revision surgeries can reach $25-31 \%(20,22,23)$. The risk of dislocation increases with time, regardless the type of surgery and in spite of adequate restoration of soft tissues $(24,25)$. At the same time, no relationship has been noted between the dislocation rate, on the one hand, and the patients' sex, age, diagnosis, and the type of endoprosthesis, on the other (26). Surgery for dislocation increases the treatment costs and health risks for the patient (15). This problem has important clinical and social implications and has no clear solution so far. 
A technical solution that can apparently prevent dislocation of endoprosthesis head is to make a non-detachable balland-socket joint. In 1952, H. G. Van Steenbrugghe was among the first to propose a total endoprosthesis of such a design, with the femoral component fixed by neck (27). In order to - among other things - reduce the risk of displacement for the acetabulum component, J. Charnley has begun implanting prostheses with a smaller head since 1960, but he still reports a dislocation rate of $1.5 \%$ in the early postoperative period $(28,29)$. Dislocation is currently prevented by using non-detachable systems. While solving the main problem, however, their use is associated with excessive wear of the friction pair, degradation of the bone-cement and cement-metal bonds, leading to aseptic loosening and a catastrophic failure of the acetabulum component (14). Even at the early stages of implant arthroplasty, one of the ways for solving the problem of hip implant dislocation was by completing the implant design with an analog of the ligamentum teres (LT). The first hip endoprosthesis of this type was proposed by Leon L. Pellet in 1954 (30).

The use of native LT or its analog as a binding element in the endoprosthesis design has not been fully developed yet. The purpose of this paper was to review relevant international experience, from the concept formation to the development and practical use of hip prostheses with native LT or its analogs, and to understand the prospects for their use and improvement. Currently, there are no systematic reviews on design of hip endoprostheses with the LT or its analogs, registered as projects in PROSPERO and COCHRANE.

\section{MATERIALS AND METHODS}

This systematic review was done in accordance with the PRISMA (Preferred Reporting Items for Systematic Reviews and Meta-analyses) Guidelines (31). The Protocol of Systematic Review of the topic in question was prepared and discussed by the team of authors. The Protocol are available upon request from the corresponding author. The basis of our review of international experience in creation and use of hip endoprostheses with native LT or its analog was the study of patent literature from the following electronic databases: Google Patents, Mountain View, CA, USA (https://patents.google.com), European Patent Organization (EPO), Rijswijk, Netherlands (https://worldwide. espacenet.com); World Intellectual Property Organization (WIPO), New York, NY, USA (https://www.wipo.int); Federal Institute of Industrial Property (FIPS), Moscow, Russian Federation (https://new.fips.ru). Since the literature on the subject is quite scanty, we did not limit the search by language or publication status. When examining the identified documents, the authors gave prefer- ence to publications in Russian and English, the languages they knew.

The initial patent search was performed in the Google Patents electronic database for the period January 1940-December 2019, inclusive. The eligibility criteria were as follows: a full-text patent describing the design of any hip prosthesis with native LT or its structural analog, or an element similar to native LT in its position and function, located inside the natural hip joint or endoprosthesis and connecting the implant head or the natural femoral head with the acetabulum of the pelvis or the acetabulum part of the endoprosthesis. The search was performed by keywords divided into three groups and connected by the Boolean operators AND and OR as follows: "ligament" OR "ligamentum" OR "ligamentum teres" OR "cord" OR "band" OR "tape") AND ("hip" OR "hip joint" OR "acetabulum") AND ("endoprosthesis" OR "prosthesis" OR "arthroplasty"). The search was complicated by the lack of a special alphanumeric code for endoprosthesis with native LT or its analog in the International Patent Classification (IPC). The closest IPC codes - A61F2002/3233, A61F2002/30688 and A61F2220/0075 - failed to identify the searched documents definitely. The lack of common terminology also contributed to search inaccuracies: e.g., "endoprosthesis" (or "prosthesis" for short) was also termed as "implant", "device", "socket" and "artificial joint". The same was observed for the LT, with its over three dozen synonyms used in the scientific and patent literature: "ligamentum capitis femoris", "ligamentum teres femoris", "ligament of head of femur", etc.

During the preliminary screening, links to patent documents displayed by the search service were manually evaluated based on the eligibility criteria for the title, the content of a brief excerpt from the text, and the accompanying graphic material. Next, each patent document - an abstract or a full text - that supposedly met the eligibility criteria was formally examined by reading the text and viewing the illustrative material. If the document met the eligibility criteria, the related documents were evaluated for compliance with these criteria: patent and non-patent publications cited therein, patent documents that cited this document, as well as similar documents from the lists available on the viewed Internet page (Patent Citations, Non-Patent Citations, Cited By, Similar Documents). Where the initial search failed to find the full-text view of a document, the search switched to the electronic platforms EPO, WIPO and FIPS. These databases were also used to ascertain the dates of the earliest publications of eligible patent documents. The search for eligible non-patent scientific publications mentioned in the related documents cited in patents was done on the Google Scholar electronic platforms (https://scholar.google.com/), PubMed (https://www.ncbi.nlm.nih.gov/pubmed/), and in available libraries. 
As the result of our search on these resources, we obtained a cohort of publications that passed the final screening. Of these, we excluded patent abstracts and abstracts of scientific reports. Then, from the number full-text publications, we excluded the descriptions of applications for invention. Next, we identified and excluded duplicates among the remaining patent descriptions evaluated as eligible and non-patent publications discussing the installation of the devices. Thus, we obtained a list of publications for the final analysis.

All the identified sources of patent information are listed in table I, in the order of their earliest priority. The nationality of patent authors was derived from the two-letter codes of countries, administrative divisions and intergovernmental organizations (WIPO ST.3). The risk of bias regarding the applicability and the rational technical essence of the identified hip prosthesis designs with native LT or its analog was ranked according to the following criteria: 1) commercial devices used in clinical practice; 2) small-batch devices used in clinical practice; 3 ) individually produced devices used in clinical practice; 4) concepts presented as a text description of the device design and installation method, with explan- atory graphic material, never used in clinical practice. The maximum risk of bias rating was assigned to endoprostheses that fell under criterion 4 , the minimum, to those under criterion 1. The risk-of-bias assessment took into account the short-term outcomes of arthroplasty described in both patent and non-patent documents. All the identified designs were grouped by the type of endoprosthesis and by the type of friction pair. Where the materials of friction pairs were either not specified, or specified too broadly or not quite clearly, the friction pair was assigned to the most likely type based on the description of the technical essence of design. Next, we analyzed the options for using native LT or its analogs in the hip endoprosthesis design, as well as analogs of the external ligaments of the hip, if available. This systematic review had no external source of funding.

\section{RESULTS}

The systematic search among 9178 patent publications identified 130 patents and applications for inventions dedicated to hip endoprostheses with native LT or its analog. Of these,

Table I. Sources of patent information.

\begin{tabular}{|c|c|c|c|c|}
\hline No. & Earliest priority & $\begin{array}{l}\text { Earliest } \\
\text { publication }\end{array}$ & Inventor/s & Patent number \\
\hline 1 & 1954-08-02 & 1956 & Pellet LL (30) & US2765787A \\
\hline 3 & 1986-10-29 & 1990 & Dudko GE (35) & SU1551366A1 \\
\hline 4 & $1987-07-06$ & 1990 & Perepichka V.D. (36) & SU1572603A1 \\
\hline 7 & $1996-07-01$ & 1998 & Dennis DA, Komistek RD (39) & US5951605A \\
\hline 8 & 1998-04-30 & 2000 & Shah MK (40) & US6010535A \\
\hline 9 & $1999-12-17$ & 2001 & $\begin{array}{l}\text { Pedersen WB, Steenstrup FR, Olsen OI, Jakobsen LD, } \\
\text { Vraa E, Lauritzen JB, Bechgaard K (41) }\end{array}$ & US7993566B2 \\
\hline 13 & $2007-09-17$ & 2009 & Linares MA (45) & US7887586B2 \\
\hline 14 & $2009-02-24$ & 2010 & $\begin{array}{l}\text { Frederick P, Belew K, Jasper L, Gatewood J, Gibson L, } \\
\text { Masonis J, Cooper M, Kelman DC (46) }\end{array}$ & US8900320B2 \\
\hline 15 & $2009-07-10$ & 2011 & Forsell P $(47)$ & US9138320B2 \\
\hline 16 & $2011-02-24$ & 2012 & Komistek RD (48) & US9023112B2 \\
\hline 17 & 2011-07-08 & 2013 & Castro FF, Fisher JMO, Moskovitz AP \$ (49) & US9060862B2 \\
\hline 18 & $2015-03-13$ & 2016 & Birmingham P (50) & US10064730B2 \\
\hline 19 & $2015-08-07$ & 2015 & Haining Z (51) & CN105105873B \\
\hline 20 & 2015-09-09 & 2015 & Boroumand S, Halwai I (52) & DE202015006363U1 \\
\hline
\end{tabular}


26 abstracts, 28 applications for inventions and 56 duplicate patent descriptions were excluded at the stages of final screening and eligibility assessment. Finally, 20 patent documents were included in the systematic review. From the 55 initially identified non-patent sources discussing various aspects of hip arthroplasty with an LT analog, including those describing short-term outcomes of the surgery, we selected two publications in Russian meeting the eligibility criteria $(32,33)$. The flowchart for selecting information sources (figure 1) follows the recommendations of Preferred Reporting Items for Systematic Reviews and Meta-Analyses (PRISMA) (31).
Eligible patent documents selected for the systematic review are presented in table $\mathbf{I}$.

Of the 20 patents selected for the systematic review, 15 were in English, 3 in Russian, 1 in German and 1 in Chinese.

The selected patents on hip endoprostheses with native LT or its analogs were grouped by the earliest priority date and presented in figure 2 . The main numbers of patents coming from $90^{\text {th }}$ years to current time. Therefore, it is possible to conclude that interest to type of hip endoprostheses with native LT has been grow up from $90^{\text {th }}$ and still remain at this level.

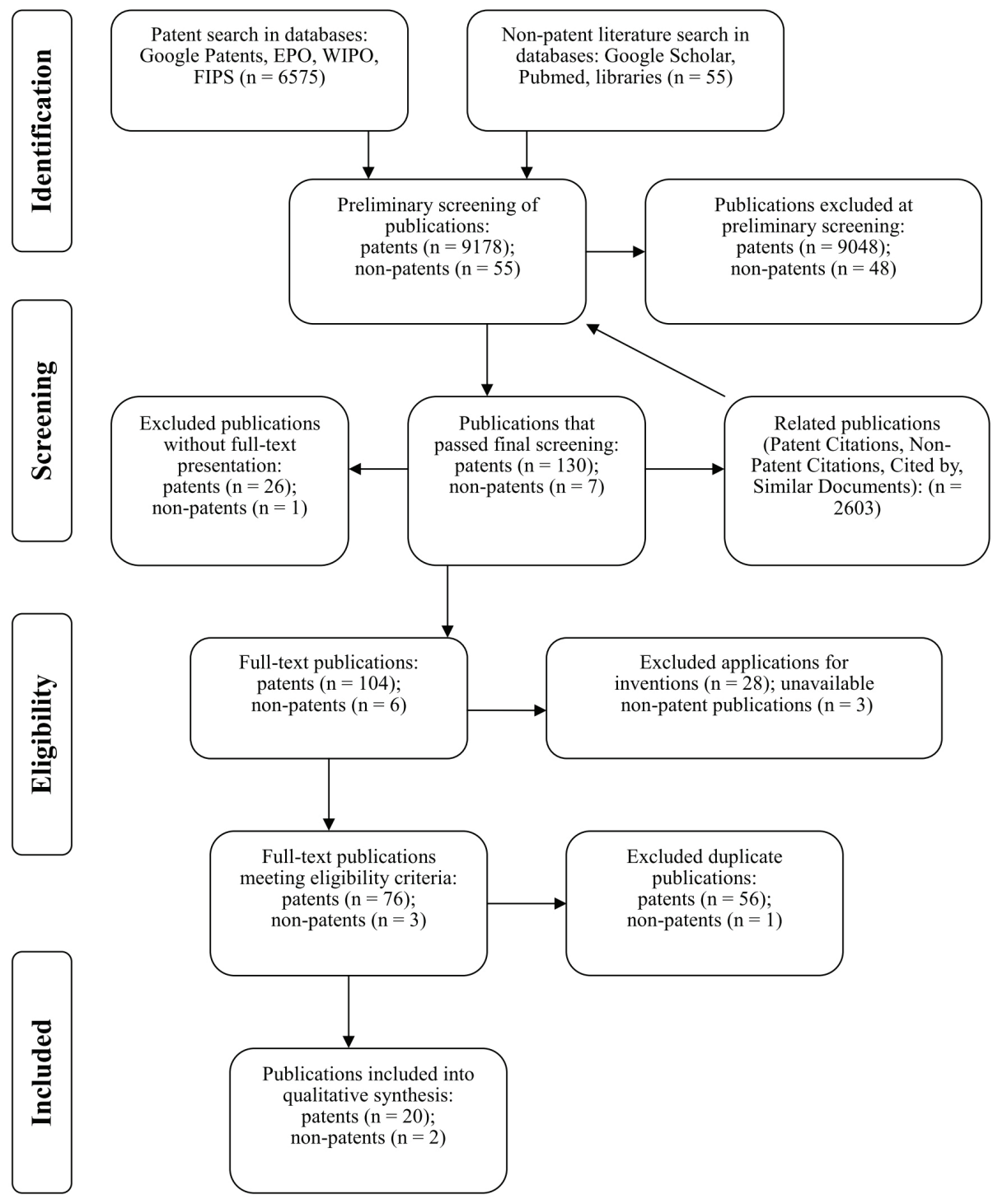

Figure 1. Flowchart of literature search according to PRISMA guidelines (31). 
We identified 40 authors of patents for invention of hip endoprostheses with native LT or its analog, their nationalities are shown in figure 3 . The dominated activity $-60 \%$ of patents was registered at the US, the second place is 17.5 -Denmark, third (10\%) Soviet Union. All the others are less than 3\%. The risk of bias regarding the applicability and the rational technical essence of identified hip prosthesis designs with native $\mathrm{LT}$ or its analogs is ranked in table II. It is no commercial endoprostheses with LT in this time. A few construction were applied at clinics, however, results are not clear.

The identified designs of endoprostheses with native LT or its analogs were grouped by type and presented in table III (see also figures 4-6).

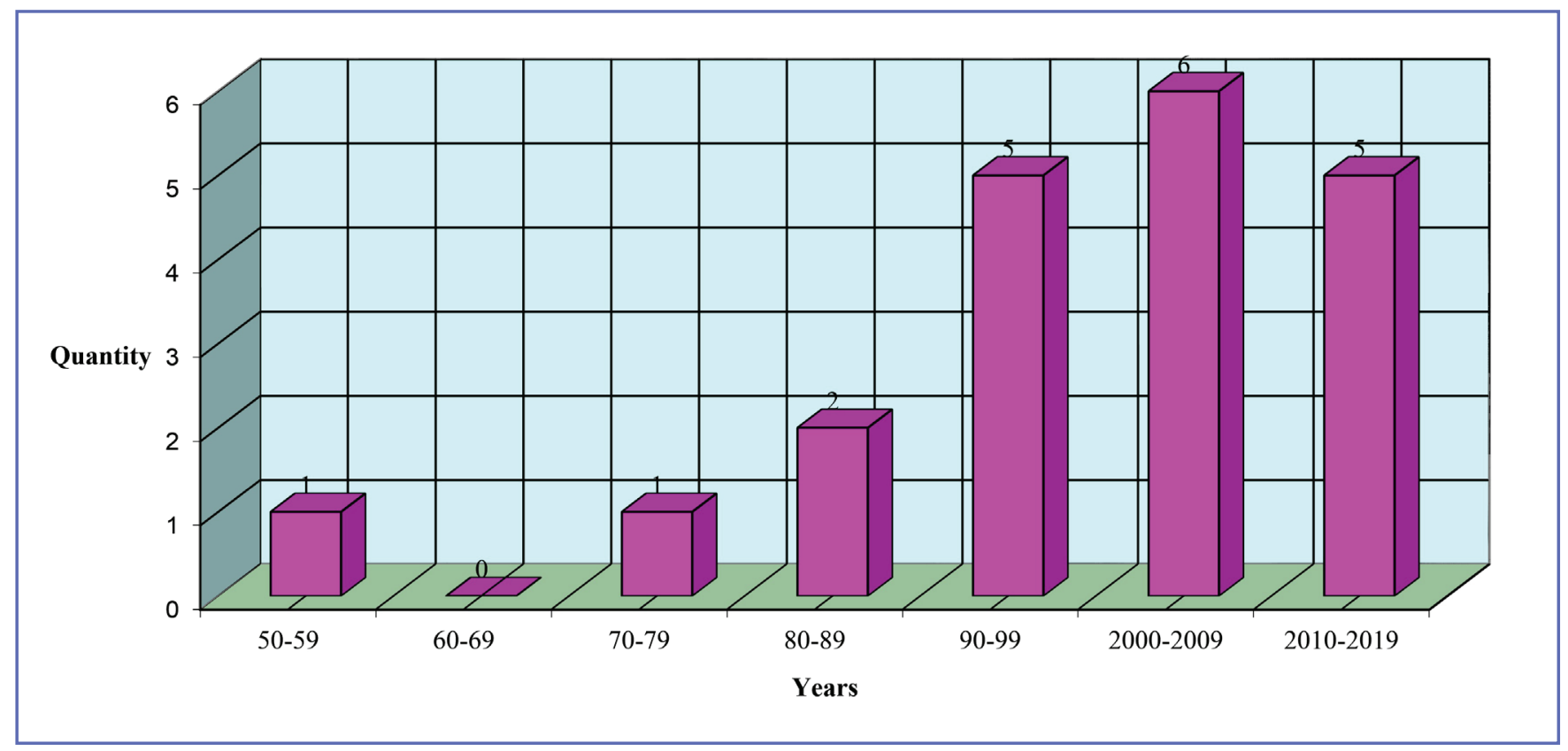

Figure 2. Patent distribution by earliest priority date

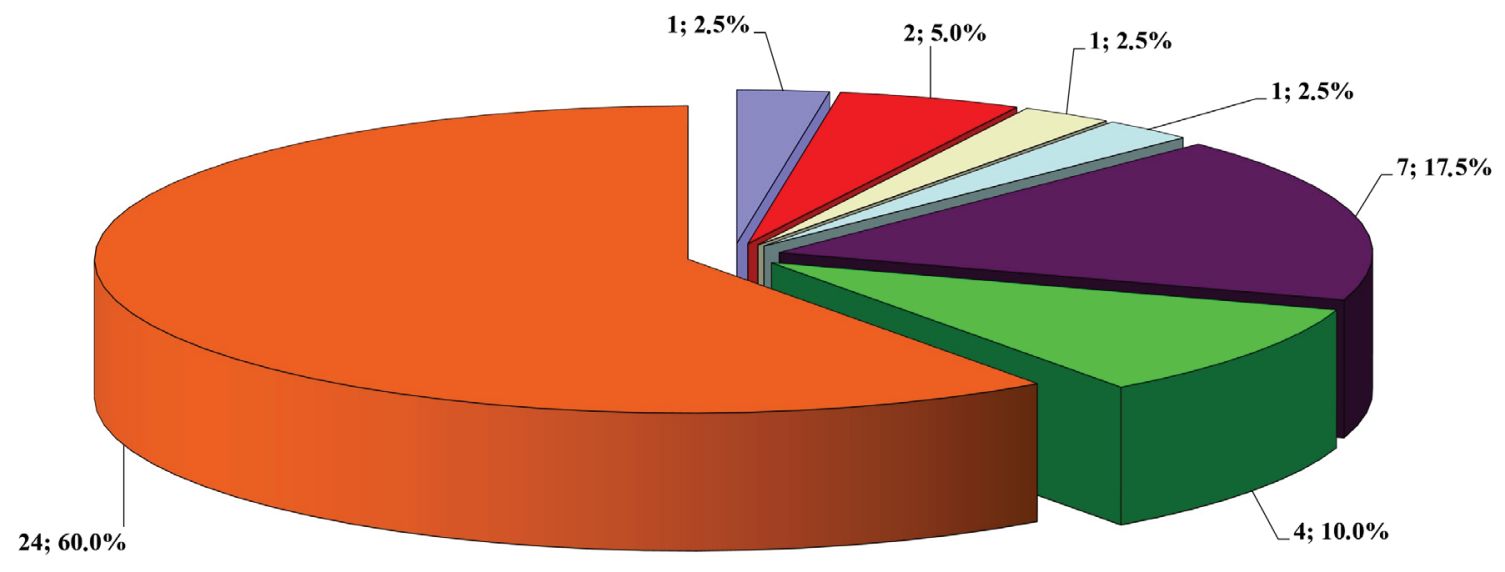

$\square \mathrm{AT} \quad \square \mathrm{CH} \quad \square \mathrm{CN} \quad \square \mathrm{DE} \quad \square \mathrm{DK} \quad \square \mathrm{SU} \quad \square \mathrm{US}$

Figure 3. Nationalities of authors of inventions. 
Table II. Risk of bias regarding endoprosthesis applicability.

\begin{tabular}{llll}
\hline Bias assessment criteria & Patent document & Non-patent document & $\begin{array}{c}\text { Risk of bias } \\
(\mathbf{1}-\mathbf{m i n} ; \\
\mathbf{4} \mathbf{m a x})\end{array}$ \\
\hline $\begin{array}{l}\text { Commercial production and use in } \\
\text { clinical practice }\end{array}$ & Not found & Not found & 1 \\
\hline $\begin{array}{l}\text { Small-batch production and use in } \\
\text { clinical practice }\end{array}$ & {$[35]$} & {$[32]$} & 2 \\
\hline $\begin{array}{l}\text { Individual production } \\
\text { and use in clinical practice }\end{array}$ & {$[37]$} & {$[33]$} & 3 \\
\hline $\begin{array}{l}\text { Design description without use in } \\
\text { clinical practice }\end{array}$ & {$[30,34,36,38-52]$} & Not found & 4 \\
\hline
\end{tabular}

Table III. Distribution of endoprostheses by the type of design.

\begin{tabular}{lll}
\hline Type & Description of design & Description of practical use \\
\hline Spacer prosthesis & {$[46]$} & Not found \\
\hline Surface replacement arthroplasty & {$[41,43,45,50]$} & Not found \\
\hline Partial endoprosthesis & {$[41,46]$} & Not found \\
\hline Unipolar partial hip endoprosthesis & {$[30,34-37]$} & {$[32,33,35,37]$} \\
\hline Bipolar partial hip endoprosthesis & Not found & Not found \\
\hline Total hip endoprosthesis & {$[38-40,42,44,45,47-49,51,52]$} & Not found \\
\hline Revision endoprosthesis & Not found & Not found \\
\hline Tumor endoprosthesis & Not found & Not found \\
\hline
\end{tabular}

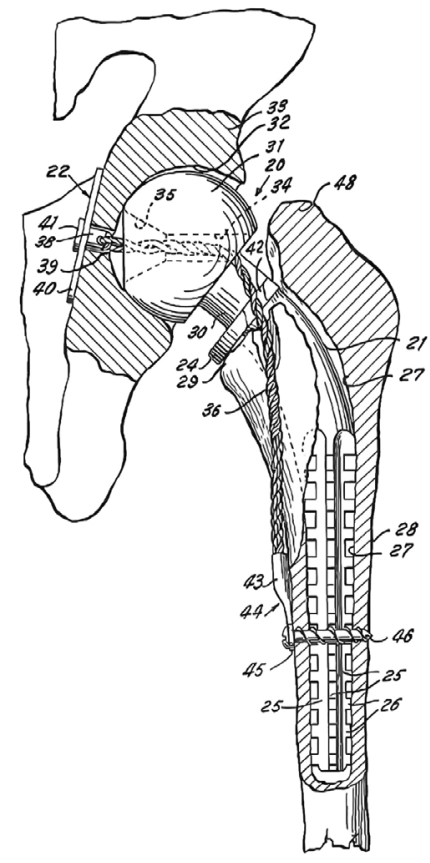

Figure 4. Unipolar partial hip endoprosthesis with an artificial LT, which is indicated by the number 36 (30).

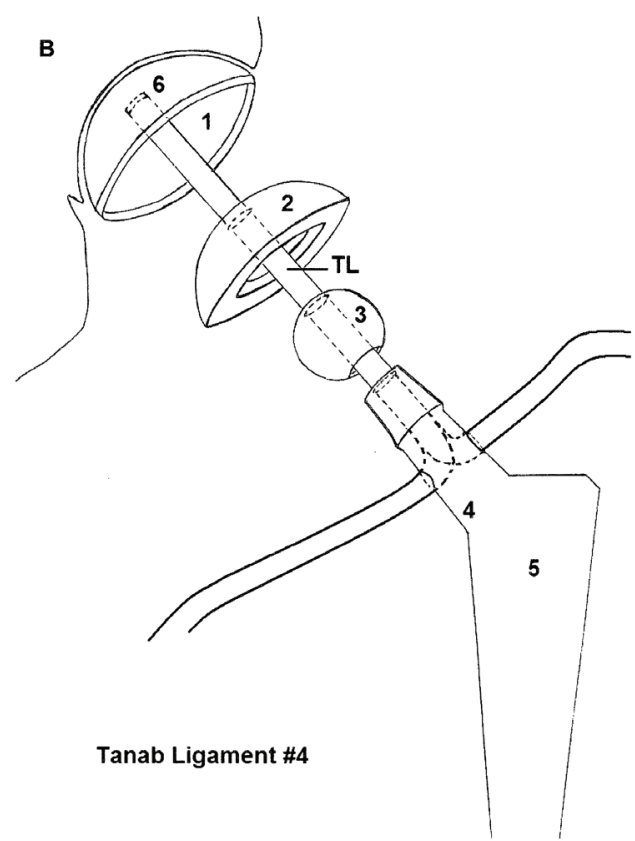

Figure 5. Total hip endoprosthesis with an artificial LT, which is indicated by the sing TL (52).

Muscles, Ligaments and Tendons Journal 2021;11 (2) 


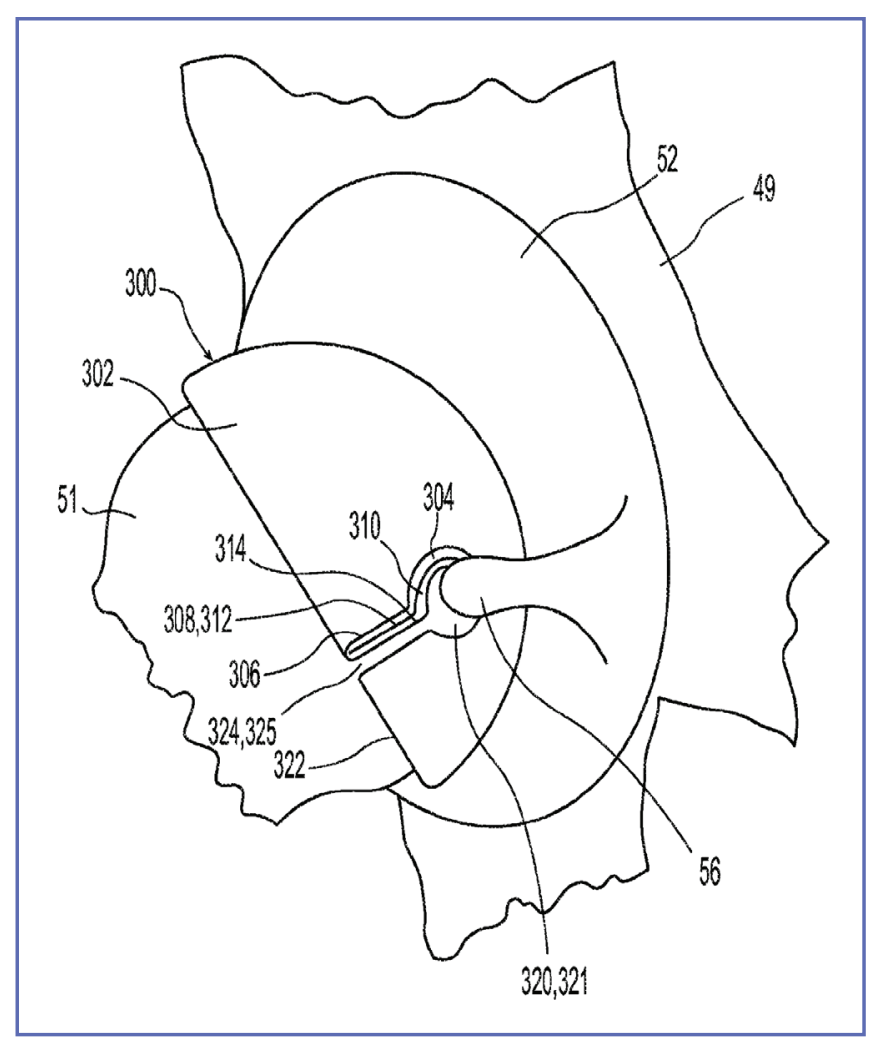

Figure 6. Surface replacement arthroplasty with the native LT, which is indicated by the number 56 (43).

The friction pair characteristics and combination of materials are of great importance for the endoprosthesis functioning. The designs of the reviewed hip prostheses with native LT or its analog were grouped by friction pair materials and presented in table IV.

\section{DISCUSSION}

Most of the hip endoprosthesis designs with native LT or its analog that passed the final screening date back to the first decade of the $21^{\text {st }}$ century. That was the period of extensive introduction of methods for hip arthroscopy and a growing use of magnetic resonance and computed tomography, and the number of publications mentioning the LT increased significantly. Another possible explanation for the fact is that the growing number of hip replacements was associated with the growing number of implant dislocations. This, again, stimulated the efforts to improve anti-luxation prostheses.

Based on the risk of bias regarding the applicability criterion, most of the proposed devices have the maximum risk rating of 4 . We have failed to identify any commercially available endoprostheses with native LT or its analog, and hence any devices with the minimum risk rating of 1 . Only two subtotal hip endoprostheses with an LT analog are known to have been used in clinical practice. The first one - a subtotal endoprosthesis designed by G.E. Dudko - has been implanted since 1984, and its risk-of-bias can be rated as 2 (35). The second one - proposed by V.A. Neverov and V.A. Shilnikov - has been used since 1990 and is assigned a risk-of-bias rating of 3 (37). The short-term outcomes of their medical use were assessed as satisfactory $(32,33$, $35,37)$. We have not succeeded in finding any long-term outcomes of these surgical interventions in the literature. Scanty publications about the practical use of hip endoprostheses with an LT analog do not allow any firm conclusions about their benefits and drawbacks. Of all known endoprosthesis designs that propose the use of native LT or its analog, 18 have never been implanted and there are no available reports on their laboratory and clinical trials. The endoprostheses with native LT and its analog included in the review fall under the existing classification of implants for hip arthroplasty. However, the specific nature of patent documentation allowed the authors to claim their proposed technical solution as belonging to several types and, in some cases, not to specify the type of design at all. We classified 11 of the identified endoprostheses as total hip endoprostheses (table III), 5 as unipolar partial hip endoprostheses (subtotal endoprosthesis, subtotal hip prosthesis system), 4 as surface replacement arthroplasty (mould arthroplasty), 2 as partial endoprostheses, and 1 as a spacer prosthesis. We failed to identify any bipolar partial hip endoprosthesis, revision endoprosthesis or tumor endoprosthesis (e.g., pelvis tumor-prosthesis) with an LT analog.

Some of the identified devices (table III) for surface replacement arthroplasty, partial acetabular rim arthroplasty and spacer endoprosthesis are claimed as intended for retainment of the LT $(41,43,46,50)$. These endoprostheses repeat the form of a part of the femoral head articular surface or the lunate surface of the acetabulum and, generally, have a horseshoe shape. However, there are some similar devices, of a similar shape (C-shaped, U-shaped, lunate), whose description has no mentioning of the LT. The technical idea behind the C-shape is to help preserve the fat pad in the acetabular fossa, preserve its blood supply, and ensure normal functioning and natural lubrication of the joint $(53,54)$.

Most of the proposed hip endoprostheses with native LT or its analog are supposed to use a metal head, less often, a polymer one, and quite rarely, a ceramic one (table IV). Some authors propose various embodiments of friction pair, which do not exclude the use of native cartilage for one of the components $(45,46,50)$. Although some inventions do not specify the type of friction pair, it can be assumed from 
Table IV. Distribution of endoprosthesis designs by the type of friction pair.

\begin{tabular}{lllll}
\hline $\begin{array}{l}\text { Material of } \\
\text { acetabular component } \\
\text { (native acetabulum/ } \\
\text { acetabular } \\
\text { component or liner) }\end{array}$ & $\begin{array}{l}\text { Material of femoral component } \\
\text { (native femoral head/head of the femoral component of endoprosthesis) }\end{array}$ & \multicolumn{3}{l}{} \\
\cline { 2 - 5 } & Cartilage & Polymer & Metal & Ceramic \\
\hline Cartilage & {$[40,41,46,50]$} & {$[34,35,37,41,45,46,50]$} & {$[30,36,46,50]$} & {$[46,50]$} \\
\hline Polymer & {$[45,46,50]$} & {$[42-45,47,50]$} & {$[38,39,42-44,47$,} & {$[42,43,47,48,50]$} \\
& & & $48,50-52]$ & \\
\hline Metal & {$[46,50]$} & {$[43,44,47,50]$} & {$[39,42-44,47,49-51]$} & {$[43,47,50]$} \\
\hline Ceramic & {$[46,50]$} & {$[43,47,50]$} & {$[43,47,50,51]$} & {$[43,47,50]$} \\
\hline
\end{tabular}

the context that their proposed endoprosthesis has a metal head $(30,36,38,39,49,51,52)$. Yet other designs do not clearly state it either, but one can surmise that the endoprosthesis head or the acetabular liner is made of a polymer material $(35,48,52)$. We have found design embodiments with a non-detachable articulating system in the form of an industrially manufactured monobloc $(42,47,49)$. In some endoprostheses, the articulation system is supposed to be enclosed by an analog of the joint capsule: a cuff or a cover made of a synthetic material (38). In rare cases, it is proposed to use a lubricant in the friction pair $(43,47)$.

Some endoprostheses use native LT, others, a modified one, and still others replace it by a specially designed analog. It is proposed that healthy native LT should be retained in surface replacement arthroplasty, spacer prosthetics and in total hip arthroplasty $(41,43,46,48,50)$. If the native LT is not healthy, it can be reinforced with an artificial structure (48). As noted in the device descriptions, an LT can be reconstructed using biological tissues (auto-, allo- or xenografts), polymer materials, and combination thereof (35-37, 39, 42, 44, 45). There are known proposals to make LT analogs of metal, in the form of rods, chains or cords $(30$, $34,38)$. Some designs provide LT analogs with a protective coating $(45,47)$, others, with a coating that carries a drug, e.g., an antibiotic (52). It has also been proposed to make an external deformable coating for LT analog and put antibiotics inside (45). Assuming that an LT analog can be damaged during its use, various methods for its repair are discussed (47).

Some endoprostheses are proposed to be supplemented with artificial analogs of external ligaments $(39,44,48)$. Here, we should note that there is a method for creating artificial external ligaments to prevent post-arthroplasty dislocation. The method was tested in practice and proved useful (55-60). The above-said supports the feasibility of supplementing hip prosthesis with native LT or its analog, analogs of external ligaments, and retaining them whenever possible during arthroplasty. The most trickly and highly specialized aspect of creating endoprosthesis with an LT analog is to provide conditions for the element functioning, proper positioning of its attachment areas, its geometric and mechanical properties. The lack of fundamental experimental and clinical studies of these issues makes it impossible to evaluate properly all data presented in the reviewed sources.

\section{CONCLUSIONS}

Among patents for inventions, we have identified 20 descriptions of various hip endoprosthesis systems which include native LT or its analog. At the same time, there is an apparent new trend in arthroplasty - creation of endoprostheses that are structurally similar to the natural joint and include the ligamentous apparatus as their structural component. There is need for further studies of mechanical impacts on an LT analog and its attachment area, the nature of its connection with the other parts of the endoprosthesis. These issues are among the least developed in this field.

Prevention of post-operative dislocations requires developing new surgical approaches and methods for placing an endoprosthesis while retaining or adequately reconstructing the natural ligamentous apparatus. The variety of the already available designs demonstrates multiple potential solutions to the pressing problems of arthroplasty, on the one hand, and the scarcity of basic data, on the other. Creating such endoprostheses seems quite realistic. However, it requires extensive preliminary research and development efforts. These devices can likely make a line of implants for staged arthroplasty, from simple and small ones, requiring minimal removal of native tissues, to complex and massive reconstructive and oncologic endoprostheses. The common distinguishing feature of the new-generation endoprostheses should be the ideology of retaining or reconstructing the ligamentous apparatus of the hip joint. 


\section{DECLARATIONS}

This work submits to the ethical standards of the Muscles, Ligaments and Tendons Journal (61). All data and material are available upon request from the corresponding author.

\section{CONTRIBUTIONS}

S.V.A: design of investigation, collecting the data and it's systematization, analysis the data, writing a draft; D.V.S:

\section{REFERENCES}

1. Judet J, Judet $R$. The use of an artificial femoral head for arthroplasty of the hip joint. J Bone Joint Surg Br 1950;32(2):166-73.

2. Bohlman HR. Replacement reconstruction of the hip. Amer J Surg 1952;94(3):268-78.

3. Thompson FR. Vital hip intramedullary prosthesis - preliminary report. NY State J Med 1952;52(24):3011-20.

4. McKeever DC. Biomechanics of hip prostheses. Clin Orthop 1961;19:87-199.

5. McKee GK, Watson-Farrar J. Replacement of arthritic hips by the McKee-Farrar prosthesis. J Bone Joint Surg Br 1966;48(2):245-59.

6. Harmon PH. Joint mobilizing operations on the hip, knee and shoulder for complications following trauma. Amer J Surg 1947;74(5):598-613.

7. Law WA. Post-operative Study of Vitallium Mould Arthroplasty of the Hip Joint. J Bone Joint Surg Br 1948;30B:76-83.

8. Stinchfield FE, Carroll RE. Vitallium-cup Arthroplasty of the Hip Joint: An End-Result Study. J Bone Joint Surg Am 1949;31A(3):628-38.

9. Newman PH, Scales JT. The unsuitability of polythene for movable weight-bearing prostheses. J Bone Joint Surg $\mathrm{Br}$ 1951;33B(3):392-8.

10. D'Aubigné RM. Reposition with arthroplasty for congenital dislocation of the hip in adults. J Bone Joint Surg Br 1952;34B(1):22-9.

11. Nissen KI. The Judet Arthroplasty of the Hip via Gibson's Lateral Approach. Postgrad Med J 1952.28(321):412-23.

12. Buxton SJ, Waugh W. Complications and difficulties of the Judet arthroplasty. J Bone Joint Surg Br 1953;35B(1):57-69.

13. Thompson FR. Experiences with a vitallium intramedullary hip prosthesis. Tex State J Med 1953;49(10):749-56.

14. Shapiro GS, Weiland DE, Markel DC, et al. The use of a constrained acetabular component for recurrent dislocation. J Arthroplasty 2003;18(3):250-8.

15. Derar H, Shahinpoor M. Recent patents and designs on hip replacement prostheses. Open Biomed Eng J 2015;9:92-102.

16. Binns M. Thompson hemi-arthroplasty through a trochanteric osteotomy approach. Injury 1985;16(9):595-8.

17. Fender D, Harper WM, Gregg PJ. Outcome of Charnley total hip replacement across a single health region in England: the results at five years from a regional hip register. J Bone Joint Surg Br 1999;81(4):577-81.

18. Berry DJ, Von Knoch M, Schleck CD, et al. Effect of femoral head diameter and operative approach on risk of dislocation after primary total hip arthroplasty. J Bone Joint Surg Am 2005;87(11):2456-63. conception and design of investigation, system analysis the data, revising the text; S.V.A and D.V.S: writing text; all authors discussed the results and commented on the manuscript at all stages.

\section{CONFLICT OF INTERESTS}

The authors declare that they have no conflict of interests.

19. Meek RM, Allan DB, McPhillips G, et al. Epidemiology of dislocation after total hip arthroplasty. Clin Orthop Relat Res 2006;447:9-18.

20. Patel PD, Potts A, Froimson MI. The dislocating hip arthroplasty: prevention and treatment. J Arthroplasty 2007;22(4 Suppl 1):86-90.

21. Parvizi J, Picinic E, Sharkey PF. Revision total hip arthroplasty for instability: surgical techniques and principles. J Bone Joint Surg Am 2008;90(5):1134-42.

22. Dargel J, Oppermann J, Brüggemann GP, et al. Luxationen nach Hüftendoprothese. Dtsch Arztebl Int 2014;111(5152):884-90.

23. Hedlundh U, Sanzen L, Fredin H. The prognosis and treatment of dislocated total hip arthroplasties with a $22 \mathrm{~mm}$ head. J Bone Joint Surg Br 1997;79(3):374-8.

24. Berry DJ, von Knoch M, Schleck CD, et al. The cumulative long-term risk of dislocation after primary Charnley total hip arthroplasty. J Bone Joint Surg Am 2004;86(1):9-14.

25. Kwon MS, Kuskowski M, Mulhall KJ, et al. Does surgical approach affect total hip arthroplasty dislocation rates? Clin Orthop Relat Res 2006;447:34-8.

26. Amlie E, Høvik $\varnothing$, Reikerås $\mathrm{O}$. Dislocation after total hip arthroplasty with 28 and $32-\mathrm{mm}$ femoral head. J Orthop Traumatol 2010;11(2):111-5.

27. Van Steenbrugghe H-G. Nouvelle prothèse articulaire à usage chirurgical [New joint replacement for surgical use] FR Patent 1953; 1047640A.

28. Charnley J. Arthroplasty of the hip. A new operation. Lancet 1961;277(7187):1129-32.

29. Charnley J. The long-term results of low-friction arthroplasty of the hip performed as a primary intervention. J Bone Joint Surg Br 1972;54(1):61-76.

30. Pellet LL. Hip arthroplasty with flexible securing means. U.S. Patent 1956;2,765,787.

31. Moher D, Liberati A, Tetzlaff J, et al. Preferred reporting items for systematic reviews and meta-analyses: the PRISMA statement. Int J Surg 2010;8(5):336-41.

32. Dudko GE. Experience with using polymer-metal endoprosthesis in the treatment of medial fractures of the femur neck in elderly patients [Опыт применения полимерно-металлического эндопротеза в лечении медиальных переломов шейки бедренной кости у пожилых]. Ortop Travmatol Protez 1990;(2):46-8.

33. Neverov VA, Shil'nikov VA. A method for forming an artificial ligament for the femur head in endoprosthe- 
sis [Способ формирования искусственной связки головки бедра при эндопротезировании]. Vestn Khir Im I I Grek 1993;151(7-12):81-3.

34. David T. Prosthetic device for use as a hip joint U.S. Patent 1978;4,092,741.

35. Dudko GE. Method of endoprosthetics of proximal end of femur [Способ эндопротезирования проксимального конца бедра] S.U. Patent 1990;1,551,366.

36. Perepichka VD. Endoprosthesis of proximal epimethaphysis of femur bone [Эндопротез проксимального эпиметафиза бедренной кости] S.U. Patent 1990;1,572,603.

37. Neverov VA, Shilnikov VA. Method for plastic surgery on thefemoral head in applying hip joint endoprosthesis [Способ пластики связки головки бедренной кости при эндопротезировании тазобедренного сустава] S.U. Patent 1992;1,743,595.

38. McCandliss R. Coaxial ligamented hip prosthesis. U.S. Patent $1997 ; 5,702,474$.

39. Dennis DA, Komistek RD. Method and apparatus for hip prosthesis. U.S. Patent 1999;5,951,605.

40. Shah MK. Joint replacement system U.S. Patent 2000;6,010,535.

41. Pedersen WB, Steenstrup FR, Olsen OI, et al. A prosthetic device U.S. Patent 2011;7,993,566 B2.

42. Stinnette A. Socket and prosthesis for joint replacement U.S. Patent 2008;7,909,882.

43. Lozier AL, Parrott RM, Rich DB. Joint space interpositional prosthetic device with internal bearing surfaces U.S. Patent 2010;8,979,935.

44. Linares MA. Hip socket with assembleable male ball shape having integrally formed ligament and female receiver and installation kit U.S. Patent 2010;8,211,182.

45. Linares MA. Artificial ligaments for joint applications U.S. Patent 2011;7,887,586.

46. Frederick P, Belew K, Jasper L, et al. Methods and apparatus for FAI surgeries U.S. Patent 2014;8,900,320.

47. Forsell P. Hip joint device and method U.S. Patent 2015;9,138,320.

48. Komistek RD. Maintaining proper mechanics THA U.S. Patent 2015;9,023,112.
49. Castro FF, Fisher JMO, Moskovitz AP. Semi-constrained ball and socket joints U.S. Patent 2013;9,060,862.

50. Birmingham P. Method and device for joint replacement U.S. Patent 2018;10,064,730

51. Haining Z. Artificial total hip joint prosthesis with axially restrained anti-dislocation structure. CN. Patent $2015 ; 105,105,873$.

52. Boroumand S, Halwai I. Tanab-Ligament [Eine bandartige Struktur, die die Luxation einer Gelenkprothese verhindert]. DE Utility model 2015;20,2015,006.

53. Urist MR. Hip socket means. U.S. Patent 1959;2,910,978.

54. Botha PJ. Joint prosthesis component WO 2006;2006/030392.

55. Nicholl JE, Bintcliffe IWL. Recurrent dislocation of a hemiarthroplasty stabilized with an $\mathrm{ABC}$ ligament. Injury 1996;27(6):447-8.

56. Fujishiro T, Nishikawa T, Takikawa S, et al. Reconstruction of the iliofemoral ligament with an artificial ligament for recurrent anterior dislocation of total hip arthroplasty. J Arthroplasty 2003;18(4):524-7.

57. Barbosa JK, Khan AM, Andrew JG. Treatment of recurrent dislocation of total hip arthroplasty using a ligament prosthesis. J Arthroplasty 2004;19(3):318-21.

58. Allington NJ, Ronda J. Use of synthetic ligament in reconstruction after massive bone tumour removal. Acta Orthop Belg 2012;78(2):263-6.

59. Hardes J, Ahrens H, Nottrott M, et al. Der Anbindungsschlauch zur Weichteilrekonstruktion nach Megaprothesenimplantation [Attachment tube for soft tissue reconstruction after implantation of a mega-endoprosthesis]. Oper Orthop Traumatol 2012;24(3):227-34.

60. Du Z, Tang S, Yang R, et al. Use of an artificial ligament decreases hip dislocation and improves limb function after total femoral prosthetic replacement following femoral tumor resection. J Arthroplasty 2018;33(5):1507-14.

61. Padulo J, Oliva F, Frizziero A, Maffulli N. Muscles, Ligaments and Tendons Journal - Basic principles and recommendations in clinical and field Science Research: 2018 update. Muscles Ligaments Tendons J 2018;8(3):305-7. 